\title{
Amiodarone Therapy for Cardiac Arrhythmias: Is It Associated with the Development of Cancers?
}

\author{
Padmavathi Mali1, Michele M. Henry Salzman², Humberto J. Vidaillet', \\ Shereif H. Rezkalla ${ }^{*}$ \\ ${ }^{1}$ Department of Cardiology, Marshfield Clinic, Marshfield, USA \\ ${ }^{2}$ Marshfield Clinic Research Foundation, Marshfield, USA \\ Email: ${ }^{*}$ rezkalla.shereif@marshfieldclinic.org
}

Received 28 January 2014; revised 3 March 2014; accepted 12 March 2014

Copyright (C) 2014 by authors and Scientific Research Publishing Inc.

This work is licensed under the Creative Commons Attribution International License (CC BY). http://creativecommons.org/licenses/by/4.0/

(c) (i) Open Access

\begin{abstract}
Amiodarone is used worldwide to treat cardiac arrhythmias, as well as highly symptomatic cases of atrial fibrillation. With this expanded use, especially following its 1985 United States Food and Drug Administration approval, and its use as a long-term therapy in common practice, reports of cancers temporarily related to amiodarone have begun to increase. Animal studies, several clinical trials, numerous case reports, and a population-based cohort study have suggested that cancers may be associated with amiodarone use. This review focuses on the ever increasing evidence in the literature that suggests amiodarone therapy, especially with long-term use, may increase the potential risk of cancer development. It also expresses the need for more definitive studies to be conducted to provide clinicians with a clear answer to this important question.
\end{abstract}

Keywords

Amiodarone; Arrhythmias; Cancer/Lung; Skin; Thyroid; Cardiac

\section{Introduction}

Amiodarone is an anti-arrhythmic drug frequently used to treat both atrial and ventricular arrhythmias. It was first developed in Europe in 1961 as an anti-anginal medication, but its potent anti-arrhythmic properties were discovered soon after. It was commonly prescribed for anti-arrhythmic uses throughout Europe and Latin

*Corresponding author.

How to cite this paper: Mali, P., et al. (2014) Amiodarone Therapy for Cardiac Arrhythmias: Is It Associated with the Development of Cancers? World Journal of Cardiovascular Diseases, 4, 109-118. http://dx.doi.org/10.4236/wjcd.2014.43017 
America before physicians in the United States (U.S.) started utilizing it in the late 1970s [1]-[3]. In December 1985, amiodarone was approved by the U.S. Food and Drug Administration (FDA) for the treatment of life threatening arrhythmias [4]. Shortly thereafter, it was also found to be very effective in managing atrial fibrillation, particularly in highly symptomatic cases.

With amiodarone's expanded use worldwide and its long-term uses, reports of cancers related to amiodarone have started to surface. This review focuses on the evidence of amiodarone therapy and the potential risk of cancer found in the literature to date.

\section{Characteristics of Amiodarone}

Amiodarone is principally categorized as a class III anti-arrhythmic agent. It is a benzofuran derivative: 2-butyl3-benzofuranyl-4-[2-(diethylamino)-ethoxy]-3,5-diiodophenyl ketone hydrochloride; $\mathrm{C}_{25} \mathrm{H}_{29} \mathrm{I}_{2} \mathrm{NO}_{3} \cdot \mathrm{HCl}$; molecular weight 681.8 [4]. It markedly prolongs the action potential of myocardial cells through blockade of potassium and sodium channels, thereby increasing the ventricular refractory period [4]-[6]. By blocking adrenergic receptors, it depresses the sinoatrial and atrioventricular (SA and AV) nodes [4]-[6]. It also produces an additional anti-arrhythmic effect through the blockade of calcium channels [6].

Typical oral maintenance doses range from $100 \mathrm{mg}$ - $400 \mathrm{mg} / \mathrm{day}$, while an intravenous maintenance infusion is generally $540 \mathrm{mg}$ over 18 hours [4] [7]. Loading doses are frequently needed, since the drug has a particularly long half-life (average 58 days, range 25 - 100 days) [4] [7].

The absorption of orally administered amiodarone is quite variable, ranging from $22 \%$ - 95\% (average 50\%) [6] [8]. It is fat-soluble and highly protein bound, so it distributes throughout the body and concentrates in highly perfused tissues such as fat, eye, gastrointestinal tract, genitourinary tract, heart, liver, lung, muscle, nervous system, skin, and thyroid [4] [8]. Metabolism occurs extensively in the liver by cytochrome P450 3A4 [4] [6]. Slow elimination from the body occurs primarily through hepatic and biliary routes, with minimal renal excretion [4] [9].

Due to its lipid solubility, high protein binding affinity, and slow elimination, amiodarone therapy, especially long-term use, leads to high concentrations of the drug accumulating in numerous organs. These properties also allow it to remain in a patient's system for weeks to months after stopping chronic amiodarone use [3] [4] [10]. This increases the potential for adverse effects such as hyper- and hypothyroidism, pneumonitis and pulmonary fibrosis, photosensitivity and skin hyperpigmentation, and hepatic dysfunction, with at least one of these effects seen in approximately 75\% of patients taking amiodarone [2] [9]. The morphological evidence of many of these adverse effects includes vacuolated cells, foamy macrophages, and/or granulomas [6]. And, since amiodarone has adverse side effects, patients should be closely monitored for their development, as well as for incidences of other side effects.

\section{Evidence of Cancer Risks Associated with Amiodarone}

\subsection{Animal Studies}

A study in rats revealed amiodarone's potential carcinogenic properties, which significantly increased the incidence of thyroid tumors such as follicular adenomas and carcinomas, in a dose-related fashion. Accompanying mutagenicity studies with amiodarone, however, proved negative [4] [11].

\subsection{Clinical Trials Reporting Cancers Associated with Amiodarone}

A meta-analysis of 15 randomized controlled trials comparing amiodarone to a placebo for the prevention of sudden cardiac death was published in 2009 [2]. It showed that amiodarone reduced the risk of sudden cardiac death by $26 \%$, cardiovascular death by $18 \%$, and generally lowered all-cause mortality compared to placebo. However, it did indicate that bradyarrhythmias were more common in patients in the amiodarone groups (2.8\% vs $1.5 \%$ in the placebo groups). There were also increases in hepatic (1.9\% vs $0.7 \%)$, pulmonary ( $2.9 \%$ vs $1.5 \%)$, and thyroid (3.6\% vs $0.4 \%$ ) toxicities in the amiodarone-treated patients compared to the placebo group patients. Of these 15 trials, 5 reported a small proportion of cancer deaths, with more cancer deaths occurring in patients randomized to amiodarone treatment [5] [10] [12]-[14].

Another trial by Roy et al. [15], which was not included in the 2009 meta-analysis by Piccini et al. [2], compared the effectiveness of amiodarone in maintaining sinus rhythm to two other anti-arrhythmic drugs (sotalol 
and propafenone) for the prevention of recurrences of atrial fibrillation. Clinically relevant adverse effects from amiodarone included pulmonary toxicity in four patients, hypothyroidism in two patients, and hyperthyroidism in one patient, all leading to amiodarone discontinuation. When assessing noncardiovascular cause mortalities, four patients died in the amiodarone treatment group and four patients died in the combined sotalol/propafenone treatment groups. Of these eight deaths, three were from noncardiovascular causes and five were from cancer. It was not further specified as to exactly which patients (amiodarone group or other groups) died from cancer or what types of cancers were involved.

These six trials indicate the development of cancers leading to death in a small proportion of the studied patients, with more cancer-related deaths occurring in patients randomized to the groups treated with amiodarone (Table 1). This demonstrates a minimal increase in cancer-related deaths associated with amiodarone, and raises the question of whether amiodarone increases the incidence of cancers in patients using it to treat cardiac arrhythmias. However, the documentation of the minimal increases in cancer incidence with amiodarone was not adequately powered to statistically analyze the differences in cancer development, thus further research was encouraged to study this.

\subsection{Case Reports Linking Amiodarone and Cancer}

A number of case reports, as well as post-market surveillance by the US FDA [4], have indicated that amiodarone therapy may increase the risk of malignancies in patients using it for the treatment of cardiac arrhythmias. Most of these reports discuss thyroid cancers, skin cancers, and lung masses (Table 2).

\subsubsection{Thyroid Cancer}

The most often seen adverse effect associated with amiodarone therapy is thyrotoxicosis, which affects up to $26 \%$ of patients and can lead to hyperthyroidism or hypothyroidism [1] [2] [16]-[18]. Hyperthyroidism is characterized by the overproduction of the thyroxine hormone. Amiodarone is thought to decrease the conversion of thyroxine to triiodothyroxine, increasing thyroxine levels. This mechanism may be due to the fact that the chemical structure of amiodarone is very similar to that of thyroxine [2]. Increased levels of iodine in the thyroid from amiodarone may also induce excess thyroid hormone synthesis, especially in the presence of an underlying thyroid disorder (e.g., goiter, Graves disease) [1] [18]. Approximately 10\% of the iodine in a tablet of amiodarone is released as a free source of inorganic iodine [1] [13] [19].

Hypothyroidism is caused by the destruction of thyroid cells, leading to a decrease in its function. The destruction is due to the abnormal development of the cells' endoplasmic reticulum and the cell death processes of necrosis and apoptosis, morphologically evidenced by deformed and disrupted follicles and focal fibrosis [1] [18] [20]. The over-saturation of the thyroid with iodine could lead to this cellular destruction.

To date, one case report has associated amiodarone-induced hyperthyroidism with thyroid cancer [17]. It follows several studies that indicate an approximate $2 \%$ - $8 \%$ association rate of thyroid cancer with hyperthyroidism, which is slightly higher than that seen in the general population with normal functioning thyroids, and state

Table 1. Randomized trials reporting amiodarone-related cancers.

\begin{tabular}{|c|c|c|c|c|c|c|c|}
\hline Trial & $\begin{array}{l}\text { Amiodarone } \\
\text { patients }\end{array}$ & $\begin{array}{l}\text { Placebo } \\
\text { patients }\end{array}$ & $\begin{array}{l}\text { Daily amiodarone } \\
\text { maintenance dose (mg) }\end{array}$ & $\begin{array}{l}\text { Follow-up } \\
\text { (months) }\end{array}$ & $\begin{array}{l}\text { Mortality } \\
\text { benefit }\end{array}$ & $\begin{array}{c}\text { Cancer in } \\
\text { placebo group }\end{array}$ & $\begin{array}{c}\text { Cancer in } \\
\text { amiodarone group }\end{array}$ \\
\hline Hamer et al. (1989) & 19 & 15 & 200 & 23 & No & 0 & $2^{*}(10.5 \%)$ \\
\hline $\begin{array}{l}\text { Ceremuzynski } \\
\text { et al. }(1992)^{10}\end{array}$ & 305 & 308 & 400 & 12 & Yes & 0 & 1 -stomach cancer $(0.3 \%)$ \\
\hline Cairns et al. $(1997)^{13}$ & 606 & 596 & 200 & 21 & Yes & 0 & $\begin{array}{c}1 \text {-metastatic } \\
\text { ovarian cancer }(0.2 \%)\end{array}$ \\
\hline Julian et al. $(1997)^{5}$ & 743 & 743 & 200 & 21 & No & $4(0.5 \%)$ & $6^{*}(0.8 \%)$ \\
\hline Elizari et al. $(2000)^{14}$ & 542 & 531 & high \& low & 6 & No & 0 & $\begin{array}{l}4^{*} \text { - determined to be } \\
\text { present prior to enrollment }\end{array}$ \\
\hline Roy et al. $(2000)^{15}$ & 201 & $\begin{array}{l}202 \text { (sotalol or } \\
\text { propafenone) }\end{array}$ & 200 & $\begin{array}{c}\text { short } \\
\text { duration }\end{array}$ & NA & $?^{*,+}$ & $?^{*,+}$ \\
\hline
\end{tabular}

${ }^{*}$ Types of cancer not specified; ${ }^{+} 4$ non-cardiac deaths occurred in the placebo group and the amiodarone group; of the 8 deaths, 5 (1.2\%) were from cancers. NA = not addressed. 


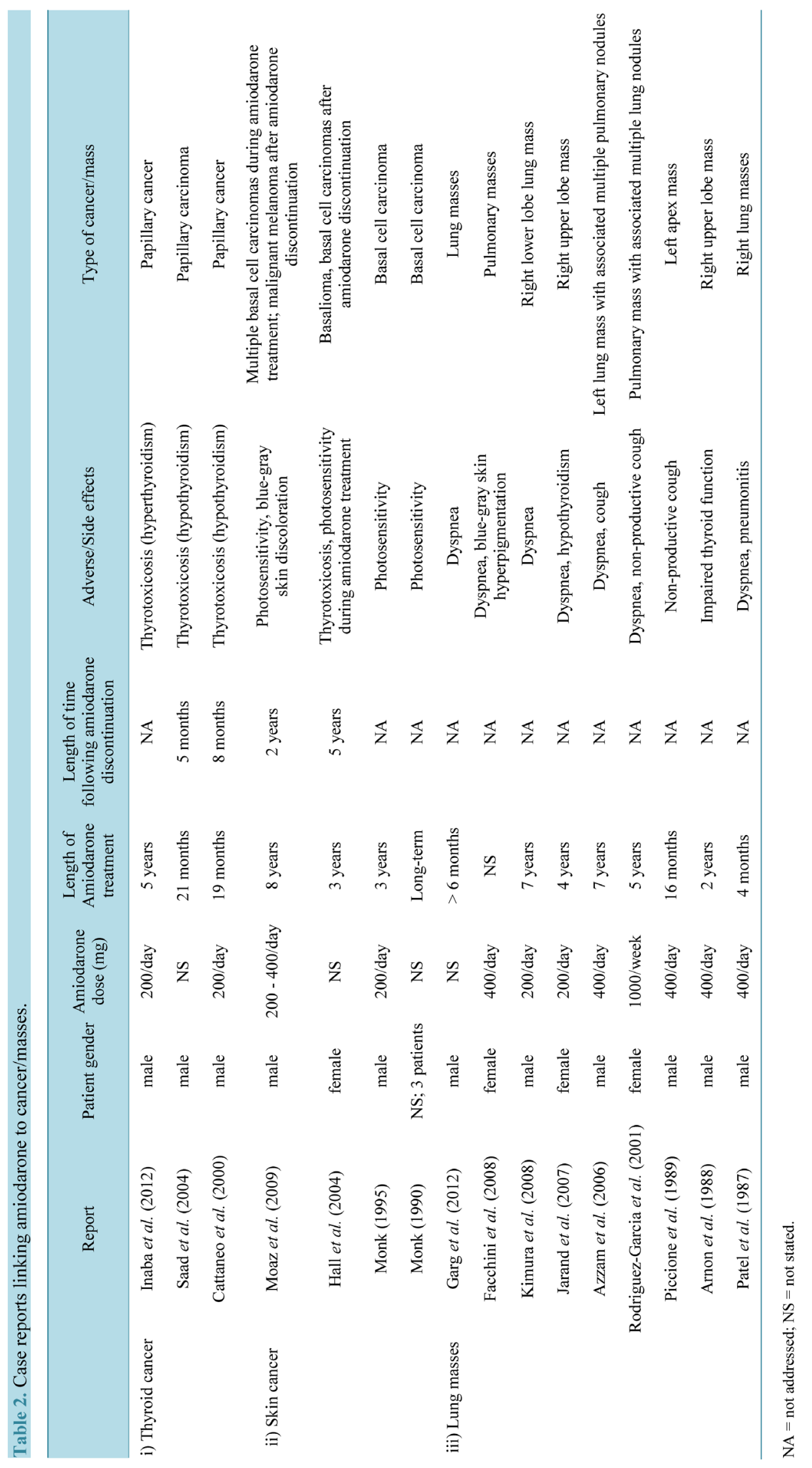


that other thyroid disorders (e.g., goiter, Graves disease) may or may not be accompanying [21]-[23]. These reports have begun to question the past thinking that hyperthyroidism lowers the risk of a patient developing thyroid cancer [24]. A couple of cases have also linked amiodarone-induced hypothyroidism to thyroid cancer [1] [24].

These reported thyroid cancers, whether associated with hyperthyroidism or hypothyroidism, developed following 2 - 5 years of amiodarone therapy or within 1 year after amiodarone discontinuation. This suggests that the accumulation of high doses of amiodarone may be needed for the development of an associated cancer, and that a latency period may also be involved [25]. In all these cases, thyroid function improved following the discontinuation of amiodarone and the appropriate thyroid dysfunction treatment. The cancers were treated accordingly, by pharmacological measures or total thyroidectomy, with the total thyroidectomy allowing the future use of amiodarone again under close monitoring.

Mutations in the BRAF gene, N-ras codon 61, H-ras codon 61, and mitogen-activated protein kinase pathway have been identified in approximately $70 \%$ of thyroid cancers [1]. However, molecular genetic analysis of the tumor tissue from the Saad et al. [1] reported case of thyroid cancer associated with amiodarone therapy found no genetic alterations that have previously been identified. This may mean that other molecular alterations and/or signaling pathways may be involved in thyroid cancers associated with amiodarone use. It has also been shown that radiation therapy may enhance the carcinogenic activity of amiodarone and/or amiodarone could amplify radiation toxicity [26].

\subsubsection{Skin Cancer}

A well-recognized side effect of long-term amiodarone treatment is photosensitivity of the skin, seen in $10 \%$ 75\% of patients [4] [9] [27] [28]. The reactions that cause the photosensitivity are most likely dose-related and occur at both UVA and UVB wavelengths, leading to intense burning, erythema, and swelling. Skin discoloration and/or hyperpigmentation, occurs in $<10 \%$ of amiodarone treated patients [7] [28]. It is mainly observed in sun exposed skin areas, most often in men, and may be preceded by photosensitivity [28] [29]. The discoloration, due to effects of ultraviolet radiation and amiodarone, may be due to the accumulation of yellow-brown pigment granules in fibroblasts and macrophages of the dermis and/or lysosomal dermal lipofuscin deposits. These side effects mainly become apparent after about 2 years of amiodarone treatment and may persist for years, even after discontinuation of amiodarone [28] [29].

To date, six cases of basal cell carcinomas (BCCs) developing during long-term (3 - 5 years) amiodarone treatment or after several years (2 - 5 years) off amiodarone, have been reported [7] [27] [28] [30]. The majority of these cases occurred in the presence of amiodarone-induced photosensitivity, and the BCCs were found in both sun-exposed skins that may have been damaged and unexposed skin. In all cases, there was no history of anything other than amiodarone use that could have triggered the BCCs; in fact, Hall et al. [7] also observed amiodarone-induced liver and thyroid effects, so amiodarone treatment was stopped. Monk [31] also mentions three more patients on amiodarone who developed BCCs, but they had other predisposing factors that could have led to the skin cancers; thus, he was cautious in his determination of whether amiodarone played a role.

No direct link between amiodarone and skin cancer has yet been made; however, the increased skin photosensitivity and/or discoloration, could be a trigger and/or provide a favorable background for the cancer [7] [28], and so remains to be studied. Also to note, amiodarone may enhance the effects of radiation therapy on the skin and mucosa, leading to exfoliative dermatitis and necrosis and oral toxicity, as well as radiation-induced cancers and/or radiation therapy may enhance the carcinogenic activity of amiodarone [9] [32].

\subsubsection{Lung Masses}

Pulmonary toxicity is the most serious adverse effect caused by amiodarone treatment according to current literature. It occurs in approximately $5 \%-17 \%$ of amiodarone treated patients, with a mortality rate of $9 \%-50 \%$, depending on the severity of the symptoms [3] [4]. The toxicity can develop within the first few days of amiodarone treatment or several years later (e.g., 7 years) and can lead to pneumonitis and pulmonary fibrosis, as well as pulmonary masses [3] [4].

Several mechanisms that may work in conjunction with each other and may involve the accumulation of iodine-rich amiodarone into pneumocytes have been suggested for amiodarone-induced pulmonary toxicity [3] [33] [34]. The first potential mechanism involves a direct toxic effect that disrupts cellular membranes through the activation of protein kinase $\mathrm{C}$, release of toxic reactive oxygen species, decreases in glutathione, mitochondrial dysfunction, necrosis, and apoptosis. An immune-mediated mechanism would lead to an imbalance of hel- 
per $\mathrm{T}$ cells and overproduction of cytokines. Over activation of the angiotensin enzyme system could induce apoptosis and the formation of fibrosis.

Numerous case reports discuss pulmonary toxicity presenting as a mass or masses in patients being treated with amiodarone [33] [35]-[42]. These masses, sometimes termed amiodaromas, were highly attenuated on computed tomography-positron emission tomography scans because of the increased incorporation of iodine into the pneumocytes, and led to concerns of cancer due to their presentation. Biopsies of the masses showed the presence of foamy macrophages and interstitial inflammation, but no evidence of malignancy. Treatment of pulmonary toxicity included the discontinuation of amiodarone use, control of risk factors, and use of corticosteroids. The therapeutic treatment value was dependent on the severity of the toxicity, and the time to resolution of symptoms varied. With so many reports of amiodarone-induced pulmonary toxicity forming masses that mimic cancer, and most of the biopsies suggesting amiodarone exposure, it may simply be a matter of time before the first case of amiodarone-induced pulmonary cancer is reported.

\section{Population-Based Cohort Study Linking Cancer Risks to Amiodarone}

Recently, Su et al. [25] performed a nationwide population-based cohort study in Taiwan to determine whether amiodarone treatment is associated with an increased risk of cancers. This was the first large scale study to focus its evaluations on the risk of cancers in patients treated with amiodarone. It included 6418 patients treated with amiodarone with a median follow up of 2.5 years. There were 280 patients who developed cancers (Table 3),

Table 3. Specific cancer types found among the patients treated with amiodarone in the Su et al. [25] study.

\begin{tabular}{|c|c|}
\hline Site of Cancer & Number Observed \\
\hline All cancers & 280 \\
\hline Digestive & 124 \\
\hline Liver and biliary & 51 \\
\hline Colon and rectum & 47 \\
\hline Genitourinary & 47 \\
\hline Lung and mediastinum & 44 \\
\hline Head and neck & 22 \\
\hline Prostate & 22 \\
\hline Stomach & 17 \\
\hline Hematologic & 14 \\
\hline All others & 12 \\
\hline Breast & 9 \\
\hline Kidney & 8 \\
\hline Bladder & 6 \\
\hline Pancreas & 6 \\
\hline Skin & 6 \\
\hline Cervix & 4 \\
\hline Uterus & 4 \\
\hline Esophagus & 3 \\
\hline Ovary & 3 \\
\hline Bone and soft tissue & 1 \\
\hline Thyroid & 1 \\
\hline
\end{tabular}


indicating a slightly significant increase in the risk of cancers among patients treated with amiodarone compared to the general population ( $P=0.067$, standardized incidence ratio $[\mathrm{SIR}]=1.12,95 \%$ confidence interval $[\mathrm{CI}]$ ). The risk was increased in men $(P=0.022$, SIR $=1.18,95 \% \mathrm{CI})$ and those patients on cumulative defined daily doses (cDDDs ) of amiodarone $>180 \mathrm{mg}$ in the first year of treatment $(P=0.046$, SIR $=1.28,95 \% \mathrm{CI})$. Patients with both these factors were at even greater risk of developing cancer $(P=0.008$, SIR $=1.46,95 \% \mathrm{CI})$. In addition, the study showed a dose-dependent effect with cDDDs greater than $180 \mathrm{mg}$ and the development of cancers, which was also previously observed in a rat study.

The lower risk of cancer occurrence in females compared to males may be due to differences in liver cytochrome P450 3A4 activity and body fat percentage. Females have increased levels of cytochrome P450 3A4, the most abundant phase I drug-metabolizing enzyme in humans, as well as an increased percentage of body fat (10\% - $13 \%$ versus $2 \%$ - $5 \%$ in males). These may work in combination to increase the clearance rate of amiodarone $\sim 37 \%$ [43]. Differences in hormonal stimuli may also play a role.

The cancers associated with amiodarone treatment that were observed most in the Su et al. [25] study occurred in the digestive tract, liver and biliary system, colon and rectum, and genitourinary system. However, thyroid cancers, skin cancers, and lung cancer-like masses are the most commonly reported in the literature to date. The Su et al. [25] investigators did not observe an increase in the risks of lung and skin cancer among the amiodarone-treated patients over that seen in the general population, and there was only minimal association with thyroid cancer observed in these patients. This may be due to the small numbers of these cancer cases, as well as other study limitations such as the relatively short follow-up, calculation of cDDDs only in the first year of amiodarone treatment, and the lack of information on other risk factors that could contribute to cancers.

\section{Conclusions}

This review discusses the ever increasing evidence suggesting that amiodarone therapy, especially long-term use, may be associated with the development of cancers. In our experience, patients started on amiodarone do require long-term therapy for the treatment and suppression of arrhythmias. Increased accumulation of amiodarone in tissues, including the thyroid, skin, and lungs, can cause adverse side effects that can then trigger mechanisms that might increase the risk of cancer development in these areas, as well as others.

The medical community needs to be alert to the development of cancers in some patients being treated with amiodarone, or who have previously taken amiodarone, and all these cancers should be promptly reported, since it is probably impractical to perform extensive routine screenings on all patients on amiodarone therapy. Also, further definitive studies, as well as other types of research, not just retrospective studies, are needed, since the majority of work so far has been with small numbers of patients and short study durations. With amiodarone being such an important drug, a definitive answer is needed to the questions of, is there a relationship between amiodarone use and the development of cancers, and is the risk of cancer worth the benefits amiodarone provides?

\section{Acknowledgements}

The authors thank the Marshfield Clinic Research Foundation's Office of Scientific Writing and Publication for assistance in the preparation and submission of this review.

\section{References}

[1] Saad, A., Falciglia, M., Steward, D.L., and Nikiforov, Y.E. (2004) Amiodarone-Induced Thyrotoxicosis and Thyroid Cancer: Clinical, Immunohistochemical, and Molecular Genetic Studies of a Case and Review of the Literature. Archives of Pathology \& Laboratory Medicine, 128, 807-810.

[2] Piccini, J.P., Berger, J.S., and O’Connor, C.M. (2009) Amiodarone for the Prevention of Sudden Cardiac Death: A Meta-Analysis of Randomized Controlled Trials. European Heart Journal, 30, 1245-1253. http://dx.doi.org/10.1093/eurheartj/ehp100

[3] Papiris, S.A., Triantafillidou, C., Kolilekas, L., Markoulaki, D., and Manali, E.D. (2010) Amiodarone: Review of Pulmonary Effects and Toxicity. Drug Saf, 33, 539-558. http://dx.doi.org/10.2165/11532320-000000000-00000

[4] United States Food and Drug Administration (2004) Medication Guide: Amiodarone HCl. NDA18-972/S-038/039, Washington DC. http://www.accessdata.fda.gov/drugsatfda_docs/label/2009/018972s038s039lbl.pdf

[5] Julian, D.G., Camm, A.J., Frangin, G., Janse, M.J., Munoz, A., Schwartz, P.J. and Simon, P. (1997) Randomised Trial 
of Effect of Amiodarone on Mortality in Patients with Left-Ventricular Dysfunction after Recent Myocardial Infarction: EMIAT. Lancet, 349, 667-674. http://dx.doi.org/10.1016/S0140-6736(96)09145-3

[6] Connolly, S.J. (1999) Evidence-Based Analysis of Amiodarone Efficacy and Safety. Circulation, 19, 2025-2034. http://dx.doi.org/10.1161/01.CIR.100.19.2025

[7] Hall, M.A., Annas, A., Nyman, K., Talme, T. and Emtestam, L. (2004) Basiloma after Amiodarone Therapy—Not Only in Britain. British Journal of Dermatology, 151, 932-933. http://dx.doi.org/10.1111/j.1365-2133.2004.06193.x

[8] Siddoway, L.A. (2003) Amiodarone: Guidelines for Use and Monitoring. American Family Physician, 68, 2189-2196.

[9] Wilkinson, C.M., Weidner, G.J. and Paulino, A.C. (2001) Amiodarone and Radiation Therapy Sequelae. American Journal of Clinical Oncology, 24, 379-381. http://dx.doi.org/10.1097/00000421-200108000-00014

[10] Ceremuzynski, L., Kleczar, E., Krzeminska-Pakula, M., Kuch, J., Nartowicz, E., Smielak-Korombel, J., et al. (1992) Effect of Amiodarone on Mortality after Myocardial Infarction: A Double-Blind, Placebo-Controlled, Pilot Study. Journal of the American College of Cardiology, 20, 1056-1062. http://dx.doi.org/10.1016/0735-1097(92)90357-S

[11] Brambilla, G. and Martelli, A. (2009) Update on Genotoxicity and Carcinogenicity Testing of 472 Marketed Pharmaceuticals. Mutation Research/Reviews in Mutation Research, 681, 209-229. http://dx.doi.org/10.1016/j.mrrev.2008.09.002

[12] Hamer, A.W., Arkles, L.B. and Johns, J.A. (1989) Beneficial Effects of Low Dose Amiodarone in Patients with Congestive Cardiac Failure: A Placebo-Controlled Trial. Journal of the American College of Cardiology, 14, 1768-1774. http://dx.doi.org/10.1016/0735-1097(89)90030-2

[13] Cairns, J.A., Connolly, S.J., Roberts, R. and Gent, M. (1997) Randomised trial of outcome after myocardial infarction in patients with frequent or repetitive ventricular premature depolarisations: CAMIAT. Lancet, 349, 675-682. http://dx.doi.org/10.1016/S0140-6736(96)08171-8

[14] Elizari, M.V., Martinez, J.M., Belziti, C., Ciruzzi, M., Perez de la Hoz, R., Sinisi, A., et al. (2000) Morbidity and Mortality Following Early Administration of Amiodarone in Acute Myocardial Infarction. European Heart Journal, 21, 198-205. http://dx.doi.org/10.1053/euhj.1999.1687

[15] Roy, D., Talajic, M., Dorian, P., Connolly, S., Eisenberg, M.J., Green, M., et al. (2000) Amiodarone to Prevent Recurrence of Atrial Fibrillation. New England Journal of Medicine, 342, 913-920. http://dx.doi.org/10.1056/NEJM200003303421302

[16] Batcher, E.L., Tang, X.C., Singh, B.N., Singh, S.N., Reda, D.J. and Hershman, J.M. (2007) Thyroid Function Abnormalities during Amiodarone Therapy for Persistent Atrial Fibrillation. The American Journal of Medicine, 120, 880885. http://dx.doi.org/10.1016/j.amjmed.2007.04.022

[17] Inaba, H., Suzuki, S., Takeda, T., Kobayashi, S., Akamizu, T. and Komatsu, M. (2012) Amiodarone-Induced Thyrotoxicosis with Thyroid Papillary Cancer in Multinodular Goiter: Case Report. Medical Principles and Practice, 21, 190-192. http://dx.doi.org/10.1159/000333697

[18] Palermo-Garofalo, C., Martinez, J.H., Silva, F., Gonzalez, E., Torres, O., Figueroa, J., et al. (2013) The Cardiology and Endocrinology Connection between Amiodarone and Thyrotoxicosis: Case Report and Review of the Literature. Boletín de la Asociación Médica de Puerto Rico, 105, 47-53.

[19] Danzi, S. and Klein. I. (2013) Amiodarone-Induced Thyroid Dysfunction. Journal of Intensive Care Medicine. (Epub ahead of print)

[20] Pitsiavis, V., Smerdely, P., Li, M. and Boyages, S.C. (1997) Amiodarone Induces a Different Pattern of Ultrastructural Change in the Thyroid to Iodine Excess Alone in Both the BB/W Rat and the Wistar Rat. European Journal of Endocrinology, 137, 89-98. http://dx.doi.org/10.1530/eje.0.1370089

[21] Taneri, F., Kurukahvecioglu, O., Ege, B., Yilmaz, U., Tekin, E.H., Cifter, C. and Onuk, E. (2005) Clinical Presentation and Treatment of Hyperthyroidism Associated with Thyroid Cancer. Endocrine Regulations, 39, 91-96.

[22] Mori, I., Miyauchi, A., Kuma, S., Tang, W. and Kakudo, K. (2003) Thyroid Nodular Lesion: Analysis of Cancer Risk Based on Kuma Hospital Experience. Pathology International, 53, 579-583. http://dx.doi.org/10.1046/j.1440-1827.2003.01530.x

[23] Oertli, D., Harder, F., Oberholzer, M. and Staub, J.J. (1998) Hyperthyroidism and Thyroid Carcinoma-Coincidence or Association? Schweizerische medizinische Wochenschrift, 128, 1910-1914.

[24] Cattaneo, F. (2000) Type II Amiodarone-Induced Thyrotoxicosis and Concomitant Papillary Cancer of the Thyroid. European Journal of Endocrinology, 143, 823-824. http://dx.doi.org/10.1530/eje.0.1430823

[25] Su, V.Y., Hu, Y.W., Chou, K.T., Ou, S.M., Lee, Y.C., Lin, E.Y., Chen, T.J., Tzeng, C.H. and Liu, C.J. (2013) Amiodarone and the Risk of Cancer: A National Population-Based Study. Cancer, 119, 1699-1705. http://dx.doi.org/10.1002/cncr.27881

[26] Bridges, A.B., Davies, R.R., Newton, R.W. and McNeill, G.P. (1989) Anaplastic Carcinoma of the Thyroid in a Patient 
Receiving Radio-Iodine Therapy for Amiodarone-Induced Thyrotoxicosis. Scottish Medical Journal, 34, 471-472.

[27] Monk, B.E. (1995) Basal Cell Carcinoma Following Amiodarone Therapy. British Journal of Dermatology, 133, 148149. http://dx.doi.org/10.1111/j.1365-2133.1995.tb02515.x

[28] Maoz, K.B., Dvash, S., Brenner, S. and Brenner, S. (2009) Amiodarone-Induced Skin Pigmentation and Multiple BasalCell Carcinomas. International Journal of Dermatology, 48, 1398-1400. http://dx.doi.org/10.1111/j.1365-4632.2008.03819.x

[29] Stahli, B.E. and Schwab, S. (2011) Amiodarone-Induced Skin Hyperpigmentation. QJM: An International Journal of Medicine, 104, 723-724. http://dx.doi.org/10.1093/qjmed/hcq131

[30] Monk, B. (1990) Amiodarone-Induced Photosensitivity and Basal-Cell Carcinoma. Clinical and Experimental Dermatology, 15, 319-320. http://dx.doi.org/10.1111/j.1365-2230.1990.tb02102.x

[31] Monk, B. (2004) Amiodarone and Basal Cell Carcinoma, Coincidence or Association? British Journal of Dermatology, 151, 933. http://dx.doi.org/10.1111/j.1365-2133.2004.06192.x

[32] De Neve, W., Fortan, L. and Storme, G. (1992) Increased Acute Mucosal and Cutaneous Radiation Toxicity in Two Patients Taking Amiodarone. International Journal of Radiation Oncology, Biology, Physics, 22, 224. http://dx.doi.org/10.1016/0360-3016(92)91008-B

[33] Azzam, I., Tov, N., Elias, N. and Naschitz, J.E. (2006) Amiodarone Toxicity Presenting as Pulmonary Mass and Peripheral Neuropathy: The Continuing Diagnostic Challenge. Postgraduate Medical Journal, 82, 73-75. http://dx.doi.org/10.1136/pgmj.2005.040105

[34] Alsamri, M.T., Pramathan, T. and Souid, A.K. (2013) In Vitro Study on the Pulmonary Cytotoxicity of Amiodarone. Toxicology Mechanisms and Methods, 23, 610-616.

[35] Patel, P., Honeybourne, D. and Watson, R.D. (1987) Amiodarone-Induced Pulmonary Toxicity Mimicking Metastatic Lung Disease. Postgraduate Medical Journal, 63, 393-394. http://dx.doi.org/10.1136/pgmj.63.739.393

[36] Arnon, R., Raz, I., Chajek-Shawl, T., Berkman, N., Fields, S. and Bar-On, H. (1988) Amiodarone Pulmonary Toxicity Presenting as a Solitary Lung Mass. Chest, 93, 425-427. http://dx.doi.org/10.1378/chest.93.2.425

[37] Piccione Jr., W., Faber, L.P. and Rosenberg, M.S. (1989) Amiodarone-Induced Pulmonary Mass. Annals of Thoracic Surgery, 47, 918-919. http://dx.doi.org/10.1016/0003-4975(89)90037-4

[38] Rodriguez-Garcia, J.L., Garcia-Nieto, J.C., Ballesta, F., Prieto, E., Villanueva, M.A. and Gallardo, J. (2001) Pulmonary Mass and Multiple Lung Nodules Mimicking a Lung Neoplasm as Amiodarone-Induced Pulmonary Toxicity. European Journal of Internal Medicine, 12, 372-376. http://dx.doi.org/10.1016/S0953-6205(01)00127-3

[39] Jarand, J., Lee, A. and Leigh, R. (2007) Amiodaronoma: An Unusual Form of Amiodarone-Induced Pulmonary Toxicity. Canadian Medical Association Journal, 176, 1411-1413. http://dx.doi.org/10.1503/cmaj.061102

[40] Facchini, G., Forte, S., Podda, P., Piro, F. and Carlone, S. (2008) Pulmonary Masses in a Patient with Blue-Gray Cutaneous Hyperpigmentation. European Review for Medical and Pharmacological Sciences, 12, 113-116.

[41] Kimura, T., Kuramochi, S., Katayama, T., Yoshikawa, T., Yamada, T., Ueda, Y. and Okada, Y. (2008) AmiodaroneInduced Pulmonary Mass and Unique Membranous Glomerulonephritis in a Patient with Valvular Heart Disease: Diagnostic Pitfall and New Findings. Pathology International, 58, 657-663. http://dx.doi.org/10.1111/j.1440-1827.2008.02286.x

[42] Garg, J., Agrawal, N., Marballi, A., Agrawal, S., Rawat, N., Sule, S. and Lehrman, S.G. (2012) Amiodarone Induced Pulmonary Toxicity: An Unusual Response to Steroids. American Journal of Case Reports, 13, 62-65. http://dx.doi.org/10.12659/AJCR.882757

[43] Araki, R., Yukawa, E., Nakashima, M.N., Fukuchi, H., Sasaki, H., Yano, K. and Nakashima, M. (2011) Population Pharmacokinetic Investigation for Optimization of Amiodarone Therapy in Japanese Patients. Therapeutic Drug Monitoring, 33, 750-756. http://dx.doi.org/10.1097/FTD.0b013e318239a728 


\section{Note List of Abbreviations and Acronyms}

$\sim$ = approximately

$\mathrm{AV}=$ atrioventricular

BCC = basal cell carcinoma

BRAF $=$ v-raf murine sarcoma viral oncogene homolog $\mathrm{B}$

$\mathrm{cDDD}=$ cumulative defined daily dose

$\mathrm{CI}=$ confidence interval

e.g. = for example

et $a l .=$ and others

FDA $=$ Food and Drug Administration

H-ras = Harvey—rat sarcoma

$\mathrm{Mg}=$ milligram

$\mathrm{NA}=$ not addressed

$\mathrm{NS}=$ not stated

$\mathrm{N}$-ras = neuroblastoma —rat sarcoma

$\%=$ percent

$\mathrm{SA}=$ sinoatrial

SIR = standardized incidence ration

U.S. = United States

UVA = ultraviolet A light rays

$\mathrm{UVB}=$ ultraviolet $\mathrm{B}$ light rays 